\title{
AS GRANDES CIDADES E A VIDA DO ESPÍRITO $(1903)^{*}$
}

Georg Simmel

Os problemas mais profundos da vida moderna brotam da pretensão do indivíduo de preservar a autonomia e a peculiaridade de sua existência frente às superioridades da sociedade, da herança histórica, da cultura exterior e da técnica da vida - a última reconfiguração da luta com a natureza que o homem primitivo levou a cabo em favor de sua existência corporal. Se o século XVIII pode clamar pela libertação de todos os vínculos que resultaram historicamente no estado e na religião, na moral e na economia, para que com isso a natureza originalmente boa, e que é a mesma em todos os homens, pudesse se desenvolver sem empecilhos; se o século XIX reivindicou, ao lado da mera liberdade, a particularidade humana e de suas realizações, dadas pela divisão do trabalho, que torna o singular incomparável e o mais indispensável possível, mas com isso o atrela mais estreitamente à complementação por todos os outros; se Nietzsche vê a condição para o pleno desenvolvimento dos indivíduos na luta mais brutal dos singulares, ou o socialismo, precisamente na manutenção do nível mais baixo de toda concorrência - em tudo isto atua o mesmo motivo fundamental: a resistência do sujeito a ser nivelado e consumido em um mecanismo técnico-social. Onde os produtos da vida especificamente moderna são indagados acerca de sua interioridade; onde por assim dizer o corpo da cultura é indagado acerca de sua alma como me parece ser atualmente o caso no que diz respeito às nossas grandes cidades —, a resposta precisa ser buscada na equalização promovida por tais formações entre os conteúdos individuais e supra-individuais da vida, nas adaptações da personalidade, mediante as quais ela se conforma com as potências que lhe são exteriores.

O fundamento psicológico sobre o qual se eleva o tipo das individualidades da cidade grande é a intensificação da vida nervosa, que resulta 
da mudança rápida e ininterrupta de impressões interiores e exteriores. O homem é um ser que faz distinções, isto é, sua consciência é estimulada mediante a distinção da impressão atual frente a que lhe precede. As impressões persistentes, a insignificância de suas diferenças, a regularidade habitual de seu transcurso e de suas oposições exigem por assim dizer menos consciência do que a rápida concentração de imagens em mudança, o intervalo ríspido no interior daquilo que se compreende com um olhar, o caráter inesperado das impressões que se impõem. Na medida em que a cidade grande cria precisamente estas condições psicológicas - a cada saída à rua, com a velocidade e as variedades da vida econômica, profissional e social —, ela propicia, já nos fundamentos sensíveis da vida anímica, no quantum da consciência que ela nos exige em virtude de nossa organização enquanto seres que operam distinções, uma oposição profunda com relação à cidade pequena e à vida no campo, com ritmo mais lento e mais habitual, que corre mais uniformemente de sua imagem sensível-espiritual de vida. Com isso se compreende sobretudo o caráter intelectualista da vida anímica do habitante da cidade grande, frente ao habitante da cidade pequena, que é antes baseado no ânimo e nas relações pautadas pelo sentimento. Pois estas lançam raízes nas camadas mais inconscientes da alma e crescem sobretudo na calma proporção de hábitos ininterruptos. Em contraposição a isto, o lugar do entendimento são as camadas mais superiores, conscientes e transparentes de nossa alma; ele é, de nossas forças interiores, a mais capaz de adaptação. Ele não necessita, para acomodar-se com a mudança e oposição dos fenômenos, das comoções e do revolver interior, sem os quais o ânimo mais conservador não saberia se conformar ao ritmo uniforme dos fenômenos. Assim, o tipo do habitante da cidade grande - que naturalmente é envolto em milhares de modificações individuais - cria um órgão protetor contra o desenraizamento com o qual as correntes e discrepâncias de seu meio exterior o ameaçam: ele reage não com o ânimo, mas sobretudo com o entendimento, para o que a intensificação da consciência, criada pela mesma causa, propicia a prerrogativa anímica. Com isso, a reação àqueles fenômenos é deslocada para o órgão psíquico menos sensível, que está o mais distante possível das profundezas da personalidade. Essa atuação do entendimento, reconhecida portanto como um preservativo da vida subjetiva frente às coações da cidade grande, ramifica-se em e com múltiplos fenômenos singulares. As grandes cidades sempre foram o lugar da economia monetária, porque a multiplicidade e concentração da troca econômica dão ao meio de troca uma importância que não existiria na escassez da troca no campo. Mas a economia monetária e o domínio 
do entendimento relacionam-se do modo mais profundo. É-lhes comum a pura objetividade no tratamento de homens e coisas, na qual uma justiça formal freqüentemente se junta com uma dureza brutal. O homem pautado puramente pelo entendimento é indiferente frente a tudo que é propriamente individual, pois do individual originam-se relações e reações que não se deixam esgotar com o entendimento lógico - precisamente como no princípio monetário a individualidade dos fenômenos não tem lugar. Pois o dinheiro indaga apenas por aquilo que é comum a todos, o valor de troca, que nivela toda a qualidade e peculiaridade à questão do mero "quanto". Todas as relações de ânimo entre as pessoas fundamentam-se nas suas individualidades, enquanto que as relações de entendimento contam os homens como números, como elementos em si indiferentes, que só possuem um interesse de acordo com suas capacidades consideráveis objetivamente - assim como o habitante da cidade grande conta com seus fornecedores e fregueses, seus criados e mesmo freqüentemente com as pessoas de seu trato de dever social, em contraposição ao caráter do círculo menor, onde o conhecimento inevitável das individualidades cria também inevitavelmente uma coloração plena de ânimo do comportamento, um estar para além da mera consideração das capacidades e compensações. Aqui, o essencial no terreno da psicologia econômica é que nas relações mais primitivas se produz para o cliente que encomenda a mercadoria, de modo que produtor e freguês se conhecem mutuamente. A cidade grande moderna, contudo, alimenta-se quase que completamente da produção para o mercado, isto é, para fregueses completamente desconhecidos, que nunca se encontrarão cara a cara com os verdadeiros produtores. Com isso, o interesse das duas partes ganha uma objetividade impiedosa, seus egoísmos econômicos, que calculam com o entendimento, não têm a temer nenhuma dispersão devida aos imponderáveis das relações pessoais. E isso está, evidentemente, em uma interação tão estreita com a economia monetária - que domina nas grandes cidades e desaloja os últimos restos da produção própria e da troca imediata de mercadorias e que reduz dia a dia o trabalho para o cliente que ninguém saberia dizer se é inicialmente aquela constituição intelectualista, anímica, que impulsiona rumo à economia monetária, ou se é esta o fator determinante daquela. Seguro é apenas que a forma da vida na cidade grande é o solo mais frutífero para essa interação, o que gostaria ainda de comprovar com a palavra do mais importante dos historiadores ingleses da constituição: no decurso de toda a história inglesa, Londres nunca foi considerada o coração da Inglaterra, mas freqüentemente seu entendimento e sempre sua bolsa! 
Em um traço aparentemente insignificante da superfície da vida unificam-se, de modo não menos característico, as mesmas correntes anímicas. O espírito moderno tornou-se mais e mais um espírito contábil. Ao ideal da ciência natural de transformar o mundo em um exemplo de cálculo e de fixar cada uma de suas partes em fórmulas matemáticas corresponde a exatidão contábil da vida prática, trazida pela economia monetária. Somente a economia monetária preencheu o dia de tantos seres humanos com comparações, cálculos, determinações numéricas, redução de valores qualitativos a valores quantitativos. Mediante a essência contábil do dinheiro chegou-se, na relação dos elementos da vida, a uma precisão, a uma segurança na determinação de igualdades e desigualdades, a uma univocidade nos acordos e combinações - tal como, externamente, foi propiciado pela difusão geral dos relógios de bolso. Contudo, são as condições da cidade grande que são tanto as causas como os efeitos desse traço essencial. As relações e oportunidades do habitante típico da cidade grande costumam ser tão variadas e complicadas, e sobretudo: mediante a acumulação de tantos homens, com interesses tão diferenciados, suas relações e atividades engrenam um organismo tão complexo que, sem a mais exata pontualidade nas promessas e realizações, o todo se esfacelaria em um caos inextricável. Se repentinamente todos os relógios de Berlim andassem em direções variadas, mesmo que apenas no intervalo de uma hora, toda a sua vida e tráfego econômicos, e não só, seriam perturbados por longo tempo. A isto se acresce, de modo aparentemente ainda mais exterior, a grandeza das distâncias, que torna toda espera e viagem perdida, uma perda de tempo insuportável. Assim, a técnica da vida na cidade grande não é concebível sem que todas as atividades e relações mútuas tenham sido ordenadas em um esquema temporal fixo e supra-subjetivo. Mas aqui também se põe em evidência o que, no final das contas, pode ser a tarefa completa destas considerações: que de qualquer ponto na superfície da existência, por mais que ele pareça brotar apenas nessa superfície e a partir dela, se pode sondar a profundidade da alma, que todas as exterioridades, mesmo as mais banais, estão ligadas, por fim, mediante linhas de direção, com as decisões últimas sobre o sentido e o estilo da vida. A pontualidade, a contabilidade, a exatidão, que coagem a complicações e extensões da vida na cidade grande, estão não somente no nexo mais íntimo com o seu caráter intelectualístico e econômico-monetário, mas também precisam tingir os conteúdos da vida e facilitar a exclusão daqueles traços essenciais e impulsos irracionais, instintivos e soberanos, que pretendem determinar a partir de si a forma da vida, em vez de recebê-la de fora 
como uma forma universal, definida esquematicamente. Se tais existências autocráticas e caracterizadas não são absoluta e completamente impossíveis na cidade, são contudo opostas ao seu tipo, e daí o ódio apaixonado pela cidade grande de naturezas como Ruskin e Nietzsche - naturezas que encontram o valor da vida não naquilo que é atribuível igualmente para todos, mas sim no que é peculiar e não-esquemático, e nas quais, portanto, brotam da mesma fonte tanto o ódio contra a economia monetária como contra o intelectualismo da existência.

Os mesmos fatores que, desse modo, na exatidão e na precisão de minutos da forma de vida, correm em conjunto rumo a uma formação da mais alta impessoalidade, atuam por outro lado de um modo altamente pessoal. Talvez não haja nenhum fenômeno anímico que seja reservado de modo tão incondicional à cidade grande como o caráter blasé. Ele é inicialmente a conseqüência daqueles estímulos nervosos - que se alteram rapidamente e que se condensam em seus antagonismos - a partir dos quais nos parece provir também a intensificação da intelectualidade na cidade grande. Justamente por isso homens tolos e de antemão espiritualmente sem vida não costumam ser blasé. Assim como uma vida desmedida de prazeres torna blasé, porque excita os nervos por muito tempo em suas reações mais fortes, até que por fim eles não possuem mais nenhuma reação, também as impressões inofensivas, mediante a rapidez e antagonismo de sua mudança, forçam os nervos a respostas tão violentas, irrompem de modo tão brutal de lá para cá, que extraem dos nervos sua última reserva de forças e, como eles permanecem no mesmo meio, não têm tempo de acumular uma nova. A incapacidade, que assim se origina, de reagir aos novos estímulos com uma energia que lhes seja adequada é precisamente aquele caráter blasé, que na verdade se vê em todo filho da cidade grande, em comparação com as crianças de meios mais tranqüilos e com menos variações.

A essa fonte fisiológica do caráter blasé da cidade grande somam-se as outras, que desaguam na economia monetária. A essência do caráter blasé é o embotamento frente à distinção das coisas; não no sentido de que elas não sejam percebidas, como no caso dos parvos, mas sim de tal modo que o significado e o valor da distinção das coisas e com isso das próprias coisas são sentidos como nulos. Elas aparecem ao blasé em uma tonalidade acinzentada e baça, e não vale a pena preferir umas em relação às outras. Essa disposição anímica é o reflexo subjetivo fiel da economia monetária completamente difusa. Na medida em que o dinheiro compensa de modo igual toda a pluralidade das coisas; exprime todas as distinções qualitativas entre elas mediante distinções do quanto; na me- 
dida em que o dinheiro, com sua ausência de cor e indiferença, se alça a denominador comum de todos os valores, ele se torna o mais terrível nivelador, ele corrói irremediavelmente o núcleo das coisas, sua peculiaridade, seu valor específico, sua incomparabilidade. Todas elas nadam, com o mesmo peso específico, na corrente constante e movimentada do dinheiro; todas repousam no mesmo plano e distinguem-se entre si apenas pela grandeza das peças com as quais se deixam cobrir. Em casos singulares, essa coloração, ou melhor, essa descoloração das coisas mediante sua equivalência com o dinheiro pode ser imperceptivelmente pequena; mas na relação do rico com os objetos que podem ser obtidos mediante dinheiro, talvez até mesmo no caráter total que o espírito público compartilha atualmente por toda parte com esses objetos, isso já se acumulou em uma grandeza bem perceptível. Eis porque as cidades grandes, centros da circulação de dinheiro e nas quais a venalidade das coisas se impõe em uma extensão completamente diferente do que nas situações mais restritas, são também os verdadeiros locais do caráter blasé. Nelas de certo modo culmina aquele resultado da compressão de homens e coisas, que estimula o indivíduo ao seu máximo de atuação nervosa. Mediante a mera intensificação quantitativa das mesmas condições, esse resultado se inverte em seu contrário, nesse fenômeno peculiar de adaptação que é o caráter blasé, em que os nervos descobrem a sua derradeira possibilidade de se acomodar aos conteúdos e à forma da vida na cidade grande renunciando a reagir a ela - a autoconservação de certas naturezas, sob o preço de desvalorizar todo o mundo objetivo, o que, no final das contas, degrada irremediavelmente a própria personalidade em um sentimento de igual depreciação.

Enquanto o sujeito se ajusta inteiramente por conta própria a essa forma de existência, a sua autoconservação frente à cidade grande exigelhe um comportamento não menos negativo de natureza social. A atitude espiritual dos habitantes da cidade grande uns com os outros poderia ser denominada, do ponto de vista formal, como reserva. Se o contato exterior constante com incontáveis seres humanos devesse ser respondido com tantas quantas reações interiores - assim como na cidade pequena, na qual se conhece quase toda pessoa que se encontra e se tem uma reação positiva com todos — - então os habitantes da cidade grande estariam completamente atomizados interiormente e cairiam em um estado anímico completamente inimaginável. Em parte por conta dessa situação psicológica, em parte em virtude do direito à desconfiança que temos perante os elementos da vida na cidade grande, que passam por nós em um contato fugaz, somos coagidos àquela reserva, em virtude da qual 
mal conhecemos os vizinhos que temos por muitos anos e que nos faz freqüentemente parecer, ao habitante da cidade pequena, como frios e sem ânimo. Decerto, se não me engano, o lado interior dessa reserva exterior não é apenas a indiferença, mas sim, de modo mais freqüente do que somos capazes de perceber, uma leve aversão, uma estranheza e repulsa mútuas que, no momento de um contato próximo, causado por um motivo qualquer, poderia imediatamente rebentar em ódio e luta. Toda a organização interior de uma vida de circulação ampliada de tal modo baseia-se em uma gradação extremamente multifacetada de simpatias, indiferenças e aversões, das mais efêmeras como das mais duradouras. A esfera da indiferença não é assim tão grande como parece superficialmente; a atividade de nossa alma responde contudo a quase toda impressão vinda de outro ser humano com uma sensibilidade determinada de algum modo, cuja inconsciência, fugacidade e mudança parece suprimila em uma indiferença. De fato, essa última ser-nos-ia tão pouco natural, assim como a indistinção de sugestões recíprocas indiscriminadas nos seria insuportável. Diante desses dois perigos típicos da cidade grande, a antipatia nos protege; antagonismo latente e estágio prévio do antagonismo prático, ela realiza as distâncias e os afastamentos, sem o que esse tipo de vida não se poderia realizar: suas medidas e suas misturas, o ritmo de seu aparecimento e desaparecimento, as formas nas quais ela se satisfaz - isso forma, com os motivos unificadores em sentido estrito, o todo indissociável da configuração da vida na cidade grande: o que aparece aqui imediatamente como dissociação é na verdade apenas uma de suas formas elementares de socialização.

Essa reserva, com o seu harmônico da aversão oculta, aparece contudo novamente como forma ou roupagem de um ser espiritual muito mais geral da cidade grande. Ela garante precisamente ao indivíduo uma espécie e uma medida de liberdade pessoal, com relação à qual não há nenhuma analogia em outras situações: com isso ela remonta a uma das grandes tendências de desenvolvimento da vida social, a uma das poucas para a qual se pode encontrar uma fórmula aproximadamente geral. O estádio mais inicial das formações sociais, que se encontra tanto nas formações históricas como naquelas que se formam atualmente, é este: um círculo relativamente pequeno, com uma limitação excludente rigorosa perante círculos vizinhos, estranhos ou de algum modo antagônicos, e em contrapartida com uma limitação includente estrita em si mesmo, que permite ao membro singular apenas um espaço restrito de jogo para o desdobramento de suas qualidades peculiares e movimentos mais livres, de sua própria responsabilidade. Assim co- 
meçam os grupos políticos e familiares, as formações de partidos, as confrarias religiosas; a autoconservação de associações muito jovens exige o estabelecimento rigoroso de limites e a unidade centrípeta e não pode portanto conceder ao indivíduo nenhuma liberdade e particularidade de desenvolvimento interior e exterior. A partir desse estádio, a evolução social bifurca-se simultaneamente para dois lados diferentes, e no entanto correspondentes. Na medida em que o grupo cresce numericamente, espacialmente, em significação e em conteúdos de vida —, então justamente afrouxa-se a sua unidade interior imediata; a pregnância da delimitação originária frente aos outros se atenua mediante relações mútuas e conexões. Ao mesmo tempo, no grupo que agora cresceu, o indivíduo ganha liberdade de movimento para muito além da delimitação inicial, invejosa, e ganha uma peculiaridade e particularidade para as quais a divisão do trabalho dá oportunidade e necessidade. Segundo essa fórmula desenvolveram-se o estado e o cristianismo, as guildas e os partidos políticos, assim como inumeráveis outros grupos, tanto mais naturalmente as condições e forças particulares do singular modificam o esquema geral. Isso também me parece ser claramente perceptível no desenvolvimento da individualidade no interior da vida citadina. A vida na cidade pequena, tanto na Antiguidade como na Idade Média, impunha ao singular, limites de movimento e de relações em direção ao exterior e de autonomia e diferenciação em direção ao interior, sob os quais o homem moderno não conseguiria respirar — ainda hoje o habitante da cidade grande sente um pouco dessa espécie de aperto ao se mudar para uma cidade pequena. Quanto menor é o tal círculo que forma o nosso meio, quanto mais limitadas as relações que dissolvem os limites perante os outros, com tanto mais inquietude ele vigia as realizações, a condução da vida e a mentalidade do indivíduo, e tanto antes uma especificação quantitativa e qualitativa explodiria o quadro do todo. Nessa direção, a antiga pólis parece ter possuído inteiramente o caráter de cidade pequena. A ameaça constante de sua existência por inimigos próximos e longínquos possibilitou aquela coesão rígida na relação política e militar, aquela fiscalização do cidadão pelo cidadão, aquele ciúme do todo diante do singular, cuja vida peculiar era mantida em tal medida em um nível baixo, que o máximo que ele tinha como compensação era o despotismo com relação a sua casa. A enorme mobilidade e agitação, o colorido único da vida ateniense explica-se talvez pelo fato de que um povo de personalidades formadas de modo incomparavelmente individual lutava contra a pressão interna e externa constante de uma cidade pequena desindividualizadora. Isso resultou em 
uma atmosfera de tensão, em que os mais fracos foram submetidos e os mais fortes foram estimulados às mais apaixonadas provas de si mesmos. E precisamente por isso ocorreu em Atenas aquele florescimento que se precisa designar, sem se poder circunscrevê-lo com exatidão, como o "universalmente humano" no desenvolvimento espiritual de nossa espécie. Pois esse é o nexo cuja validade tanto objetiva como histórica aqui se assevera: os conteúdos e formas de vida os mais amplos e universais estão intimamente ligados com os mais individuais; ambos têm seu estádio prévio comum, ou mesmo seu opositor comum, nas configurações e agrupamentos restritos, cuja autoconservação defendem tanto contra a amplitude e universalidade que lhes é exterior, como contra o que se move livremente e é individual em seu interior. Assim como na época feudal o homem "livre" era aquele que estava sob o direito comum, isto é, sob o direito do maior círculo social, mas não era livre quem extraía seu direito apenas do círculo restrito de uma corporação feudal, sob a exclusão daquele outro - assim ocorre hoje, em um sentido mais refinado e espiritualizado, com o habitante da cidade grande, que é "livre" em contraposição às miudezas e prejuízos que limitam o habitante da cidade pequena. Pois a reserva e indiferença mútuas, as condições espirituais de vida dos círculos maiores, nunca foram sentidas tão fortemente, no que diz respeito ao seu resultado para a independência do indivíduo, do que na densa multidão da cidade grande, porque a estreiteza e proximidade corporal tornam verdadeiramente explícita a distância espiritual. Decerto é apenas o reverso dessa liberdade se, sob certas circunstâncias, em nenhum lugar alguém se sente tão solitário e abandonado como precisamente na multidão da cidade grande; pois aqui, como sempre, não é de modo algum necessário que a liberdade do ser humano se reflita em sua vida sentimental como um sentir-se bem. Não é apenas a grandeza imediata do distrito e o número de pessoas que, em virtude da correlação histórico-universal entre a ampliação do círculo e a liberdade pessoal, interior e exterior, tornam a cidade grande o local dessa última, mas sim o fato - ultrapassando essa amplitude de visão - de que as cidades grandes são também os locais do cosmopolitismo. De modo comparável à forma do desenvolvimento financeiro - a partir de uma determinada grandeza a propriedade desenvolve-se em progressões cada vez mais rápidas e como que por si mesma —, o círculo de visão, as relações econômicas, pessoais e espirituais da cidade, os seus arredores ideais, assim que ultrapassam um determinado limiar, ampliam-se como em progressão geométrica. Toda expansão dinâmica realizada torna-se patamar para uma nova ex- 
pansão, não igual, mas maior. Junto aos fios que são tecidos por ela crescem continuamente outros novos, como por si mesmos, exatamente do mesmo modo como no interior da cidade o unearned increment da renda da terra conduz o proprietário a ganhos que brotam de si mesmos, mediante o simples aumento do tráfico. Nesse ponto a quantidade da vida converte-se de modo muito imediato em qualidade e caráter. A esfera de vida da cidade pequena é, no principal, fechada em si mesma e consigo mesma. Para a cidade grande, é decisivo o fato de que sua vida interior se espraia em ondas sobre um território nacional ou internacional mais amplo. Weimar não é nenhum contra-exemplo, pois sua significação estava ligada a personalidades singulares e morreu com elas, enquanto a cidade grande se caracteriza precisamente em virtude de sua independência essencial, mesmo com relação às personalidades singulares mais significativas - a contrapartida e o preço da independência que o singular desfruta em seu interior. A essência mais significativa da cidade grande repousa nessa grandeza funcional, para além de seus limites físicos: e essa atuação sua atua de volta sobre si mesma e dá peso, consideração e responsabilidade a sua vida. Assim como um ser humano não se esgota nos limites de seu corpo ou do distrito que ele preenche com sua atividade imediata, mas somente na soma dos efeitos que se irradiam dele temporal e espacialmente: assim também uma cidade constitui-se da totalidade de seus efeitos, que ultrapassam o seu imediatismo. Só esse é o seu âmbito real, no qual se exprime o seu ser. Isso já indica que a liberdade individual, a complementação lógica e histórica dessa amplitude, não deve ser compreendida apenas em sentido negativo, como mera liberdade de movimento e ausência de preconceitos e filisteísmos. Seu traço essencial é de fato que a particularidade e incomparabilidade que, no final das contas, toda natureza possui, se exprime na configuração da vida. Que sigamos as leis da própria natureza - e isso é decerto liberdade —, só nos é claro e convincente, assim como aos outros, quando as manifestações dessa natureza se distinguem também das dos outros; somente a sua nãointercambialidade com as dos outros comprova que nosso modo de existência não nos é imposto pelos outros. Inicialmente, as cidades são o local da mais elevada divisão econômica do trabalho; elas criam assim fenômenos tão extremos como, em Paris, a lucrativa profissão de quatorzième: pessoas, que se dão a conhecer por letreiros em suas casas, que à hora do jantar estão prontas, com trajes adequados, a serem rapidamente convocadas a participar de jantares em que o número de pessoas à mesa seja treze. Precisamente na medida de sua expansão, a 
cidade oferece cada vez mais as condições decisivas da divisão do trabalho: um círculo que, mediante a sua grandeza, é capaz de absorver uma variedade extremamente múltipla de realizações, ao mesmo tempo em que a concentração dos indivíduos e sua luta pelo cliente coagem o singular a uma especialização das realizações, na qual ele não possa ser tão facilmente desalojado por um outro. O decisivo é que a vida citadina metamorfoseou a luta com a natureza por obtenção de alimento em uma luta entre os homens, de sorte que o ganho que se disputa não é concedido pela natureza, mas sim pelos homens. Pois nisso atua não somente a fonte mencionada da especialização, mas também uma mais profunda: aquele que oferece precisa tratar de criar necessidades sempre novas naqueles que corteja. A necessidade de especializar as realizações a fim de encontrar uma fonte de ganho ainda não esgotada, uma função que não seja facilmente substituível, estimula a diferenciação, o refinamento, o enriquecimento das necessidades do público, que acabam evidentemente por conduzir a variedades pessoais crescentes no interior desse público.

E isto desemboca em uma individualização espiritual (em sentido estrito) dos atributos anímicos, propiciada, em virtude de sua grandeza, pela cidade. É evidente uma série de causas. Inicialmente, a dificuldade de fazer valer a própria personalidade nas dimensões da vida na cidade grande. Onde o aumento quantitativo de significação e energia se aproxima de seus limites, o homem agarra-se à particularização qualitativa, a fim de, por meio do excitamento da sensibilidade de distinção, ganhar de algum modo para si a consciência do círculo social: o que conduz finalmente às mais tendenciosas esquisitices, às extravagâncias específicas da cidade grande, como o exclusivismo, os caprichos, o preciosismo, cujo sentido não está absolutamente no conteúdo de tais comportamentos, mas sim em sua forma de ser diferente, de se destacar e, com isso, de se tornar notado para muitas naturezas definitivamente o único meio de resguardar para si, mediante o desvio pela consciência dos outros, alguma auto-estima e preencher um lugar na consciência. No mesmo sentido atua um momento inaparente, mas recorrente, em seus efeitos decerto perceptível: a brevidade e raridade dos encontros que cada singular concede aos outros - comparado com o tráfico na cidade pequena. Pois dessa forma a tentação de se apresentar do modo o mais característico, gracioso, concentrado fica muito mais forte do que onde um se encontrar longa e freqüentemente propicia aos outros uma imagem inequívoca da personalidade.

Esse me parece ser o motivo mais profundo pelo qual justamente a cidade grande sugere a pulsão rumo à existência pessoal a mais individual - 
pouco importa se sempre com razão e com sucesso. O desenvolvimento da cultura moderna caracteriza-se pela preponderância daquilo que se pode denominar espírito objetivo sobre o espírito subjetivo, isto é, tanto na linguagem como no direito, tanto na técnica de produção como na arte, tanto na ciência como nos objetos do âmbito doméstico encarna-se uma soma de espírito, cujo crescimento diário é acompanhado à distância cada vez maior e de modo muito incompleto pelo desenvolvimento espiritual dos sujeitos. Se considerarmos, por exemplo, a cultura monstruosa que se encarnou nos últimos 100 anos em coisas e conhecimentos, em instituições e bem-estar, e a compararmos com o progresso da cultura dos indivíduos no mesmo tempo - pelo menos nos estratos mais elevados —, vemos uma diferença de riqueza terrível entre as duas, e mesmo, em muitos pontos, um retrocesso da cultura dos indivíduos com relação à espiritualidade, delicadeza e idealismo. Essa discrepância é essencialmente o sucesso da divisão do trabalho; pois esta exige do singular uma realização cada vez mais unilateral, cuja potencialização freqüentemente deixa atrofiar a sua personalidade como um todo. De qualquer modo, o indivíduo está cada vez mais incapacitado a se sobrepor à cultura objetiva. Ele foi rebaixado a uma quantité négligeable, a um grão de areia em uma organização monstruosa de coisas e potências, que gradualmente lhe subtraiu todos os progressos, espiritualidades e valores e os transladou da forma da vida subjetiva à forma da vida puramente objetiva, talvez de modo menos consciente do que na prática e nos obscuros sentimentos que dela se originam. Basta notar que as grandes cidades são os verdadeiros cenários dessa cultura, que cresce para além de tudo o que é pessoal. Nas construções e instituições de ensino, nos milagres e confortos da técnica, que domina o espaço, nas formações da vida em comum e nas instituições visíveis do estado revela-se um espírito que se tornou tão impessoal, que se cristalizou em uma multiplicidade de tal modo imponente, que a personalidade, por assim dizer, não se pode contrapor a isso. Por um lado, a vida torna-se infinitamente mais fácil, na medida em que estímulos, interesses, preenchimentos de tempo e consciência se lhe oferecem de todos os lados e a sugam em uma corrente na qual ela praticamente prescinde de qualquer movimento para nadar. Mas, por outro lado, a vida compõe-se cada vez mais desses conteúdos e programas impessoais, que pretendem recalcar as colorações verdadeiramente pessoais e o que é incomparável. E isso de tal modo, que para salvar o que há de mais pessoal é preciso convocar o que há de extremo em peculiaridade e particularização, e é preciso exagerá-las para que se possa tornar audível, inclusive para si mesmo. A atrofia da cultura individual mediante a hipertrofia da cultura objetiva é um fundamento do ódio 
irado que os pregadores do individualismo extremo, Nietzsche à frente, nutrem contra as grandes cidades; mas é também uma razão pela qual eles são tão apaixonadamente queridos precisamente nas grandes cidades, pois surgem ao habitante destas últimas como os arautos e redentores de sua mais insaciável nostalgia.

Na medida em que se pergunta pela posição histórica das duas formas de individualismo, que são providas pelas relações quantitativas da cidade grande: a independência individual e a formação do modo pessoal e específico, a cidade grande ganha um valor completamente novo na história universal do espírito. O século XVIII encontrou o indivíduo em ligações violentadoras, que se tornaram sem sentido, de tipo político e agrário, corporativo e religioso - limitações que coagiam os homens como que a uma forma não natural e a desigualdades há muito injustas. Nesta situação surgiu o clamor por liberdade e igualdade - a crença na completa liberdade de movimento do indivíduo em todas as relações sociais e espirituais, que permitiria evidenciar imediatamente em tudo o seu núcleo nobre e comum, tal como a natureza o teria semeado em todos e a sociedade e a história o teriam apenas deformado. Ao lado desse ideal do liberalismo cresceu no século XIX, por um lado por intermédio de Goethe e do Romantismo, por outro por meio da divisão econômica do trabalho, a idéia de que os indivíduos, libertos das ligações históricas, querem então também se distinguir uns dos outros. Agora o suporte de seu valor não é mais o "homem universal" em cada singular, mas sim precisamente a unicidade e incomparabilidade qualitativas. Na luta e nas escaramuças mútuas desses dois tipos de individualismo, a fim de determinar o papel dos sujeitos no interior da totalidade, transcorre a história interior e exterior de nossa época. A função das cidades grandes é fornecer o lugar para o conflito e para as tentativas de unificação dos dois, na medida em que as suas condições peculiares se nos revelam como oportunidades e estímulos para o desenvolvimento de ambas. Com isso as cidades grandes obtêm um lugar absolutamente único, prenhe de significações ilimitadas, no desenvolvimento da existência anímica; elas se mostram como uma daquelas grandes formações históricas em que as correntes opostas que circunscrevem a vida se juntam e se desdobram com os mesmos direitos. Mas com isso - sejam-nos simpáticos ou antipáticos seus fenômenos singulares - elas saem completamente da esfera perante a qual nos é adequada a atitude do juiz. Na medida em que tais potências penetraram na raiz e na coroa de toda a vida histórica, a que pertencemos na existência fugidia de uma célula, nossa tarefa não é acusar ou perdoar, mas somente compreender ${ }^{1}$. 


\section{Nota do tradutor}

"As grandes cidades e a vida do espírito" ("Die Grossstädte und das Geistesleben") - também conhecido como "A metrópole e a vida mental" - é o texto de uma conferência proferida por Georg Simmel (18581918) por ocasião da Exposição das Cidades, ocorrida em Dresden, Alemanha, no inverno de 1902-03. Durante este evento, outros intelectuais alemães da época também proferiram conferências, mas a de Simmel foi, de longe, a de melhor fortuna. Trata-se, entretanto de um rearranjo de idéias já há tempos divulgadas pelo autor, pelo menos desde o final da década de 1880, e que ele já tivera, àquela altura, oportunidade de apresentar em um de seus livros mais importantes, a Filosofia do dinheiro, publicado em 1900 (um livro que tem em comum com a Interpretação dos sonhos não somente o ano de sua publicação). Com efeito, a conferência de 1903 é uma espécie de versão ampliada do capítulo final de Filosofia do dinheiro, intitulado "O estilo de vida". Não obstante, trata-se de um recorte especialmente feliz, que permitiu em poucas páginas sintetizar as linhas mestras das idéias expostas na segunda parte do livro de 1900. Não por acaso, Simmel, ao final da conferência, remete seus leitores a este mesmo livro, no qual tudo se encontra melhor desenvolvido. Ambos, o livro e a conferência, tornaram-se - embora em momentos e com ênfases variadas textos clássicos das ciências sociais.

É justamente essa a razão que justifica a publicação da presente versão em Mana, mas não somente. Os leitores brasileiros e portugueses há muito conhecem "A metrópole e a vida mental" (do inglês "The Metropolis and Mental Life"), que chegou até nós em uma coletânea intitulada O fenômeno urbano, organizada por Otávio Velho, e publicada ao final dos anos 1960. Desde a década seguinte, Gilberto Velho passou a incorporar as reflexões de Simmel em seus trabalhos, de tal modo que o destino dessa conferência parece estar, em nosso país, definitivamente ligado ao PPGAS/Museu Nacional. Não surpreende, portanto, que em 2005, um grupo de pesquisadores desta instituição tenha se reunido para ler a Filosofia do dinheiro - pois como Simmel muito bem percebeu, quem herda não rouba.

Sei que irei morrer sem herdeiros espirituais (e é bom que seja assim). Meu espólio é como uma herança em dinheiro vivo, que é dividida entre muitos herdeiros: cada um converte a sua parte em alguma aquisição de acordo com a sua natureza, de modo que não se pode enxergar a sua proveniência daquele espólio 
Embora na hora de sua morte Simmel não tenha nomeado herdeiros, eles não deixaram de proliferar desde então.

Sobre a tradução. Como, por um lado, a tradução dos anos 1960 foi baseada na tradução norte-americana do texto de Simmel (uma vertente poderosa na história de sua recepção) e, por outro, o livro no qual ela foi publicada se encontra há muito esgotado, julguei válido oferecer uma tradução a partir do texto original, tomado agora do sétimo volume da edição das obras completas de Georg Simmel, ainda em curso pela editora Suhrkamp de Frankfurt-am-Main. A bibliografia nacional e internacional sobre Simmel, por sua vez, oferece amplos e variados materiais para subsidiar e ampliar a discussão desse texto notável, razão pela qual esta nota se abstém de fazê-lo.

\section{Notas}

* Texto original: "Die Großstädte und das Geistesleben". In: SIMMEL, Georg. Gesamtausgabe. Frankfurt: M. Suhrkamp. 1995. vol. 7. pp. 116-131. Tradução de Leopoldo Waizbort.

${ }^{1} \mathrm{O}$ conteúdo desta conferência, por sua própria natureza, não remonta a uma literatura própria. A fundamentação e apresentação de suas principais idéias históricoculturais é dada pela minha Philosophie des Geldes. 